\title{
Effect of Tea Polyphenol on Serum Hormone, Serum Enzyme Activity and Antioxidant-Related Gene Expression in Chinese Yellow Chicken under Heat Stress
}

\author{
Mingxuan Yang ${ }^{1}$, Yinglin Lu ${ }^{1}$, Qizhao Zhu, Peng Gao, Xiaolei Xie, Debing Yu* \\ ${ }^{+}$Department of Animal Genetics, Breeding and Reproduction, College of Animal Science and \\ Technology, Nanjing Agricultural University, 210095 Jiangsu Province, PR China Molecular and Cellular \\ Biology
}

${ }^{1}$ The authors contributed equally to this study.

"Corresponding author:College of Animal Science and Technology, Nanjing Agricultural University, No.1 Weigang Road, Nanjing City 210095, Jiangsu Province, China; E-mail: yudebing@njau.edu.cn (Yu.DB) ; Tel: +86-25-84395036, Fax: +86-25-84395314

\begin{abstract}
The present study was conducted to evaluate the effects of dietary supplementation of tea polyphenol (TP) on serum hormone, serum enzyme activity, antioxidant-related and immune-related gene expression of laying hens under heat stress. A total of 288 Chinese yellow chicken (186 days old) were randomly distributed among two treatments, each of which included 6 replicates of 24 hens. Dietary treatments were that the basal diet was supplemented with $200 \mathrm{mg}$ / kg tea polyphenol. The study lasted for 7 weeks, including 1 week of adaptation and 6 weeks of the formal test. The content of high-density lipoprotein cholesterol (HDL-C) and total protein (TP) in serum significantly decreased by dietary supplementation with tea polyphenol. Dietary tea polyphenol supplementation improved serum superoxide dismutase (SOD), glutathione peroxidase (GSH-Px) enzyme activity and decreased serum malondialdehyde (MDA) content in treatments compared to the control. However, supplementation of tea polyphenol did not affect the activity of serum catalase (CAT). The results indicated that long-term feeding of tea polyphenols help to increase the amount of hormones ( $\mathrm{FSH}_{1} \mathrm{E}_{2}$ ) associated with reproduction in laying hens and thus improve egg production. It also improved the immune function of laying hens in high temperature environments. Adding tea polyphenols to the diet can significantly increase the serum IgG, IgM content of the laying hens and can upregulate the IgA content. Dietary supplementation of tea polyphenols in the laying hens significantly increased the expression of antioxidant enzyme-related genes (SOD, CAT and GPX1) in the liver. Moreover, the addition of tea polyphenols significantly increased the expression of immune-related genes (Interferon- $\gamma($ INF- $\gamma)$, Interleukin 2 (IL-2) and Interleukin 4 (IL-4)) in the spleen. It is concluded that addition of tea polyphenols has a positive effect on antioxidant activity and immune function of laying hens.
\end{abstract}

Keywords: tea polyphenol; Serum hormone; enzyme activity; immune function, enzyme-related genes

\section{Introduction}


Heat stress causes significant hyperthermia and results in reduction of egg production, egg weight, ovarian weight, and the number of large follicles, which can lead to a significant reduction in plasma progesterone, $17 \beta$-estradiol, testosterone and luteinizing hormone $[1,2]$ and affects mRNA expression of cytochrome P450 17- $\alpha$ hydroxylase and steroidogenic enzymes in the hen ovary [1]. Heat-stressed rat granulosa cells showed a time-dependent increase in apoptosis [3]. It appears from the above studies that heat stress directly affects reproductive function in vertebrates. However, an alternate explanation for these previously observed reproductive effects is that heat stress can have negative impacts on egg production and reproductive performance through the effect on feed intake and physiological characteristics of laying hens $[4,5]$. Decreased feed intake is known to affect the endocrine system, leading to acid-base imbalances and organ dysfunction [6]. In addition, heat stress may also result in decreased immune function [7]. High-temperature environmental stress also increases both the incidence and severity of infections from pathogens such as Salmonella and Campylobacter in farm animals [8]. In fact, many domestic chickens are severely affected by natural heat stress due to location of tropical or subtropical regions [6, 9]. Recently, nutritional strategies have been proposed that can be used to improve the tolerance of birds to heat stress, such as dietary reduction of protein $[10,11]$ or energy and the introduction of dietary supplements $[12,13]$. With the focus on the animal health, more and morenatural and safe feed additives have become the primary choice for farms. These feed additives were mainly from some natural plants extraction. Studies have shown that curcumincan be used as a feed additive to enhance the antioxidant properties of laying hens [14], and isoflavones in soybeans can be used as additives to increase progesterone secretion from chicken granulosa cells [15]. Probiotics have also been reported as feed additives to slow the rate of reproductive aging [16].Additionally, there are many studies that Chinese herbal medicine can be used as a safe feed additive, such as the effect of Astragalus membranaceus on the gut microbiota of laying hens [17]. Therefore, such natural additives have a broad prospect in animal production.

Polyphenols are key biologically active compounds in tea. Epigallocatechin-3-gallate (EGCG), which accounts for $50-80 \%$ of total catechins in tea, is considered to be the most biologically active catechin in green tea [18]. The mechanism of action of EGCG has been proposed to involve inflammation, oxidative stress and various molecular signalling pathways as targets for EGCG [19]. Studies have shown that dietary supplements of $200 \mathrm{mg} /$ $\mathrm{kg}$ of tea polyphenols can improve the performance of older hens, protein and a large number of forms [20]. Tea polyphenol can also prevent atherosclerosis [21]. Studies have shown that L-theanine in tea can regulate immunity, regulate the secretion of Th1 and Th2 cytokines, and supplement L-theanine can increase serum interleukin-2 (IL-2) and interferon gamma (IFN- $\gamma$ ) content [22]. However, there are few reports on the supplementation of tea polyphenols as feed additives to improve antioxidant properties and immune functions in animals, especially in relieving heated-stress states.

The female Chinese yellow chicken are offen used to lay, so in somewhere, these chickens can be regarded as a laying line, but they are subjected to effect of natural environment.

Therefore, the objective of this study was to evaluate the effects of tea polyphenols supplementation on serum antioxidant enzymes, serum hormones, immune function and 
related genes content in Chinese yellow chicken under heat stress.

\section{Materials and Methods}

\subsection{Ethics Statement}

This experimental protocol was approved by the Ethical Committee and conducted under the supervision of the Institutional Animal Care and Use Committee of Nanjing Agricultural University, Nanjing, China.

\subsection{Experimental Birds, Design, and Feed Preparation}

In this study, 288 186-day-old layer-type China native yellow chickens were assigned to 96 cages for seven weeks (one week of adaptation, six weeks of experimental period), completely randomized (CRD). The hens were randomly divided into 2 experimental groups, each with 6 replicates, with each replicate containing 24 chickens. Relative humidity was maintained at 50\%, with temperature and humidity measured daily. Environment was kept clean and well-ventilated. Diets were prepared according to the normal nutritional needs of laying hens in China (Table 1).

Tea polyphenols were obtained from Wuxi Sanzhi Biotechnology Co., Ltd., Jiangsu, China. The laying hens were divided into two groups, the control group: the basic diet; the treatment group: $200 \mathrm{mg} / \mathrm{kg}$ tea polyphenols were added to the basal diet. The experiment was conducted from July 15 to August 26, 2018, and exposed to high temperature for 7 hours every day $(10: 00 \mathrm{am}-17: 00 \mathrm{pm})$, with an average daily temperature of $32{ }^{\circ} \mathrm{C} \pm 2$. Samples were taken after the end of the experiment and 6 hens from each group were randomly selected.

\subsection{Assay of Serum Biochemical Parameters}

At the end of the feeding period, six blood samples $(3 \mathrm{~mL})$ from each treatment were collected from a wing vein using a sterile syringe and needle. After equilibration at room temperature for 30 minutes, serum was obtained by centrifugation at $3500 \times \mathrm{g}$ for 15 minutes. Serum samples were stored at $-20^{\circ} \mathrm{C}$ to determine serum parameters.

Serum cholesterol (CHO), total protein (TP), triglyceride (TG), albumin (ALB), high-density lipoprotein cholesterol (HDL-C), low-density lipoprotein cholesterol (LDL-C), glucose (GLU), aspartate aminotransferase (AST), alanine aminotransferase (ALT) and alkaline phosphatase (ALP) levels were determined by biochemical automatic analysis.

\subsection{Assay of Enzyme Activities and Endocrine Hormones}

Superoxide dismutase (SOD), glutathione peroxidase (GPx), catalase (CAT) and malondialdehyde (MDA) [23] activities were assayed in serum using commercial kits (Nanjing jiancheng) [24]. Corticosterone (COR), oestradiol (E2), follicle stimulating hormone (FSH), luteinizing hormone (LH) were measured by ELISA. (Nanjing jiancheng)

\subsection{Assay of Immune Activity}

The IgG, IgA, IgM, complement C3, complement C4, IL-6 were measured by ELISA. The assay kit was purchased from Aoqing Biological Co., Ltd, and the reagent preparation and 
procedure were carried out according to the instructions. Main instruments: incubator, constant temperature water bath, oscillator.

\subsection{RNA Extraction and Quantitative Real-Time PCR Assay}

TRIzol reagent was used to extract total RNA from the liver and spleen. The total RNA concentration was determined using a Thermo Nano Drop 2000 (Thermo Fisher Scientific Inc., Waltham, USA). Reverse transcription was then performed in which the reaction system (20 $\mu \mathrm{L}$ ) contained $4 \mu \mathrm{L}$ of total RNA. Next, the cDNA was produced through reverse transcription, and the cDNA was diluted to a desired concentration $(400 \mathrm{ng} / \mathrm{uL})$ for quantitative real-time PCR.

The mRNA expression levels of antioxidant enzyme-related genes - SOD, CAT, GPx1 and heat shock protein 90 (HSP90) in the liver were analysed using quantitative real-time PCR. Similarly, quantitative real-time PCR was used to analyze the mRNA expression levels of the anti-immunological related genes Interferon- $\gamma$ (INF- $\gamma$ ), Interleukin 2 (IL-2) and Interleukin 4 (IL-4) in the spleen. The primers used in this study were designed by Primer 3.0 software (Premier Biosoft International, Palo Alto, CA) and synthesized by GENEWIZ Biotechnology Company (Nanjing, China) (Table 2). Using the following procedure, the system used for quantification is $20 \mu \mathrm{L}$, qRT-PCR was performed in triplicate: $95{ }^{\circ} \mathrm{C}, 8$ minutes, 35 cycles, $95{ }^{\circ} \mathrm{C}$ for 10 seconds, $60{ }^{\circ} \mathrm{C}$ for 15 seconds, $72{ }^{\circ} \mathrm{C}$ for 10 seconds, $72{ }^{\circ} \mathrm{C}$ for 10 minutes. The target genes and the $\beta$-actin primer sequence are listed in Table 2 . The relative expression levels of target gene mRNAs were analysed by comparing CT values $(2-\Delta \Delta \mathrm{CT})$.

\subsection{Statistical Analysis.}

All data were analysed using SPSS Version 20.0 for Windows and expressed as the mean values with pooled standard errors of the mean using one-way ANOVA. Differences were considered statistically significant at $\mathrm{P}<0.05$ and highly significant at $\mathrm{P}<0.01$, unless otherwise stated.

\section{Results}

\subsection{Effects of TP on Serum Biochemical Parameters}

Changes in serum parameters at the end of 42 days of feeding were observed as follows (Table 3): TP (total protein) content in treatment significantly decreased by $9.49 \%(\mathrm{P}<0.05)$ compared with the control. There was also a significant difference in serum HDL-C (high density protein) content between the two groups; treatment decreased by $54.1 \%(\mathrm{P}<0.05)$ compared with the control.

\subsection{Effect of TP on Serum Antioxidant Indices}

It is well known that SOD, GSH-PX, CAT and MDA are the four main indicators reflecting the antioxidant status of laying hens[25], so we determined the activity of SOD, GSH-PX, CAT and the MDA content of serum. Table 4 reflects the serum antioxidant index after 42 days of feeding with the tea polyphenol additive. From the four indices, it can be seen that the serum antioxidant index did not change significantly after 42 days of feeding, but it still followed the trend of SOD, GSH-PX, CAT increasing and MDA decreasing. 


\subsection{Effect of TP on Reproductive Hormones}

Table 5 reflects serum hormone levels 42 days after the administration of tea polyphenols. Compared with the control group, the serum COR level in the treatment group decreased by $12.5 \%(\mathrm{P}<0.05)$; concentration of FSH in the treatment group was significantly higher than that of the control group by $17.15 \%(\mathrm{P}<0.05)$.

\subsection{Effects of TP on Immune Parameters}

Table 6 shows the immune status of laying hens after 42 days of tea polyphenol feeding. Compared with the control group, the levels of serum IgG and IgM in the treatment group were significantly increased by $36.76 \%$ and $31.64 \%(\mathrm{P}<0.05)$, respectively.

\subsection{Expression of Antioxidant-related Genes in the Liver}

It can be seen from Figure 1 that after 42 days of adding tea polyphenols to the diet, the expression levels of SOD and GPX1 mRNA in the liver of the laying hens were significantly higher than those in the control group under heat stress $(\mathrm{P}<0.05)$. However, the expression of CAT mRNA in liver was significantly decreased $(\mathrm{P}<0.05)$, and there was no significant difference in the expression of HSP90 mRNA. This is consistent with the change in the previously measured antioxidant index, which demonstrates that the addition of tea polyphenols increases the antioxidant properties of laying hens.

\subsection{Expression of Immune-related Genes in the Spleen}

The effects of tea polyphenols on the levels of INF- $\gamma$, IL-2 and IL-4 in spleen of laying hens were measured. As shown in Figure 2, after feeding the polyphenols diet for 42 days, it was observed that the spleen INF- $\gamma$, IL-2 and IL-4 mRNA expression levels were significantly increased in the treated group compared with the control group $(\mathrm{P}<0.01)$.

\section{Discussion}

Flavonoids are found in beverages such as vegetables, fruits, grains, nuts, cocoa and tea. Flavonoids have antioxidant and anti-inflammatory effects. Flavonoids mainly include luteolin, velutin, orange peel, nobileten, kaempferol, quercetin, apigenin, myricetin and catechins from tea [26]. The subject of this experiment is a tea polyphenol which is a component of catechin. This test aims to determine whether tea polyphenols can be fed to laying hens as a natural antioxidant feed additive to reduce heat stress caused by high temperatures in summer. In recent years, many studies have demonstrated the therapeutic effects of flavonoids on some diseases, such as insulin resistance [26]. Also useful as a supplement to agents for the treatment of arthritis and other autoimmune diseases [27]. It has been confirmed that polyphenols have a mitigating effect on stomatitis and dental disease [28]. Studies have also shown that epigallocatechin-3-gallate (EGCG) protects against kidney disease and demonstrates that EGCG acts as an antioxidant by inhibiting excessive production of ROS caused by stress or irritation [29]. (-)-Epigallocatechin-3-gallate (EGCG), occupying $50-80 \%$ of the total catechins in tea, is considered to be the most chemically active catechin in green tea [18]. Previous research has shown that EGCG has the capacity to scavenge toxic reactive metabolic wastes [30]. Other studies demonstrated that the likely 
mechanisms of EGCG are oxidative stress, inflammation, and different molecular signalling pathways as the targets of EGCG [19]. Therefore, we speculated that the addition of tea polyphenols to basal diets may be associated with antioxidant properties and immune function. According to our experiments, in the presence of heat stress the addition of tea polyphenols can effectively improve the antioxidant performance of laying hens and the immune function of laying hens. Hormone levels also improved. Additionally, the addition of polyphenols increases the expression level of antioxidant-related genes.

\subsection{Effects of TP on Serum Biochemical}

After 42 days of feeding the diet supplemented with tea polyphenols, it was found that the total protein content (TP) in the serum of the treated group and the control group decreased significantly. EGCG in polyphenols has a certain alleviation effect on many chronic and cardiovascular diseases, especially cardiovascular diseases [31]. The increase in total protein content may be caused by some liver diseases[32]. Therefore, we speculate that the addition of tea polyphenols is also effective in preventing liver diseases.

\subsection{Effects of TP on Antioxidation}

From the antioxidant index data measured in the serum, it was found that the SOD, GSH-Px content of the treated group was increased, and the MDA level was lowered as compared with the control group. With the development of modern intensive farming, chickens are prone to oxidative stress [33]. Antioxidants (SOD, CAT, GSH-Px and MDA) are the first lines of defence against oxidative damage [34]. Through previous research, we know that a high temperature environment can induce oxidative stress in the body [35]. The good antioxidant properties of EGCG in tea polyphenols [36] remind us that intervention can improve the antioxidant performance of laying hens. The results showed that feeding a diet supplemented with tea polyphenols in a high temperature environment can increase the antioxidant content of laying hens, thereby improving the antioxidant performance.

\subsection{Effects of TP on Hormone Levels}

During the development of chicken ovary and follicles, a strict follicular development system was established through natural selection and follicular atresia, allowing these follicles to develop in a certain order [37, 38]. Egg production is currently one of the most profitable industries in animal production. Gonadotropins, such as FSH and LH, play a particularly important role in follicular development [39]. FSH can promote the secretion of P4 in follicular granulosa cells at some stages of follicular development [38]. In addition, LH can also promote the secretion of P4 [40, 41]. E2 promotes follicular development through feedback to the hypothalamus and pituitary [42]. Therefore, we measured the levels of FSH, LH and E2 in the serum of laying hens under different treatments. These indicators can be used to reflect the laying performance of laying hens [43]. The result is that feeding a diet supplemented with tea polyphenols in a high temperature environment can significantly increase the FSH content in the serum of laying hens. An increase in FSH content can stimulate follicular growth and maturation and promote the production of heavy oestrogen in follicles. It can be concluded that tea polyphenols have a beneficial effect on the laying performance of laying hens. 
Corticosterone is the major glucocorticoid released by the adrenal cortex of rodents, birds and reptiles [44]. When released into the peripheral circulation, CORT binds to intracellular glucocorticoid receptors, which usually respond to stress in some animals [45, 46]. From the results obtained in this experiment, after adding tea polyphenols to the laying hens' diet in a high temperature environment, the corticosterone content in the serum was significantly lower than that of the control group. It can be concluded that tea polyphenols play a very important role in relieving heat stress in laying hens.

4.4 Effects of TP on Immune Activity

As mentioned earlier, many studies have shown that polyphenols have a therapeutic effect on inflammatory diseases. Green tea polyphenols or EGCG treatment have been shown to effectively inhibit chronic psoriasis pruritus in mice. Moreover, the itching relief of EGCG can be attributed to its antioxidant and anti-inflammatory properties [47]. This provides strong preclinical evidence for tea polyphenols to improve immune function. Studies have revealed a new role of green tea polyphenol EGCG in regulating Ca 2+ entry into murine CD4 $+\mathrm{T}$ cells and human leukemia T cell lymphoblasts [48], thereby improving immune function. It has also been shown to relieve allergic symptoms [49]. Serum immunoglobulin concentration, as a parameter reflecting the immune function in animals, plays an important role in combating various infections and diseases [50]. To the best of our knowledge, few studies have investigated the complementary effects of TP on serum immune responses in laying hens at high temperatures. The results of this experiment showed that diets supplemented with tea polyphenols in a high temperature environment increased the levels of serum IgA, IgG and IgM in laying hens compared with the control group, and the IgG and IgM content increased significantly. It can be concluded that feeding supplemental tea polyphenols will increase the immune function of laying hens in high temperature environments. However, further research is needed to draw some conclusions about the dietary effects of tea polyphenols on immune responses.

4.5 Effects of TP on Genes Expression of Antioxidant Enzymes in the Liver

Previous studies have shown that SOD is the first enzyme to fight $\mathrm{O} 2$ radicals and important endogenous antioxidants against oxidative stress, and GSH-dependent enzymes (GST, GPx and GR) are resistant to peroxidative damage [51]. Increased expression of antioxidant-related genes, the liver's antioxidant defense system is greatly activated to resist oxidative damage caused by heat stress and balance the body's oxidation and antioxidant levels [52]. The enhanced motor activity (SOD) of antioxidants, CAT and GPX1) leads to increased defense against oxygen and free radicals in laying hens. The result of this experiment was that the expression levels of total RNA SOD and GPX1 in the liver were up-regulated in the tea polyphenol supplement group. The HSP90 gene is expressed when stressed. It can be seen from the results of this study that there was a downward trend in the expression of HSP90 in the liver of the laying hens compared with the control group, but the difference was not significant. Consistent with our results, Simona Rimoldi et al [53] found no difference in HSP90 mRNA expression between the two groups. It is speculated that this may be due to chronic heat stress. Collectively, these results indicate that the tea polyphenol-fed hens have a better antioxidant status than the control.

4.6 Effects of TP on Genes Expression of Immune-related in the Spleen

INF- $\gamma$ is a pluripotent cytokine produced by activated $\mathrm{T}$ lymphocytes and plays an 
important regulatory role in the immune system. It not only activates macrophages but also activates NK cells [54]. And it is a highly potent antiviral cytokine with broad-spectrum immunomodulatory effects [55]. It is reported that the beginning of IL-2 function depends on $\mathrm{B}$ and $\mathrm{T}$ lymphocytes, which is one of the most important lymphoid factors regulating the immune function of the body [56]. Similarly, the function of Th2 relies on the secretion of IL-4 and other cytokines to stimulate humoral immunity [57]. INF- $\gamma$ and IL-2 are mainly expressed by Th1 cells, while IL-4 is mainly expressed by Th2 cells, which play important roles in mediating cellular and humoral immune responses, respectively[58]. Therefore, we determined the contents of INF- $\gamma$, IL-2 and IL-4 in the total RNA of spleen tissues of laying hens by real-time fluorescence quantitative determination. Compared with the control group, the results showed that tea polyphenols significantly increased the levels of IL-2, INF- $\gamma$ and IL-4 in the spleen of laying hens under heat stress. An increase in the expression levels of these immune factors suggests that the addition of tea polyphenols may exert an immunomodulatory response by improving the balance of Th1/Th2. The quantitative results are similar to changes in the immune-related factors measured in serum. It is further proved that the supplementation of tea polyphenols can effectively regulate the immune function of laying hens under heat stress mode.

\section{Conclusion}

This study shows that the addition of tea polyphenols in high-temperature environments has an effect on increasing the antioxidant capacity, increasing the expression of antioxidant-related genes in the liver, improving immune function, enhance the expression of immune-related factors in the spleen, and increasing hormones associated with reproduction to increase the amount of egg production. The experimental results show that tea polyphenols play an important role in relieving heat stress in laying hens. Therefore, tea polyphenols can be used as natural and safe antioxidants to improve the adverse effects of high temperature environments on laying hens.

Acknowledgments: We really appreciated the reviewer and the editor helped us for English correction, especially about grammar during the whole process of our revision. We also thank Dr. Paula.R Chen from University of Missouri for her kind help during the first revision. This study was supported We thank to the Agricultural Independent Innovation Project of Jiangsu Province for providing the fund for successful implementation of the project (CX(17)3014) and Jiangsu Natural Science Research Foundation (BK2015433).

\section{References:}

1. Rozenboim I, Tako E, Gal-Garber O, Proudman JA, Uni Z: The effect of heat stress on ovarian function of laying hens. Poultry science 2007, 86(8):1760-1765.

2. Novero RP, Beck MM, Gleaves EW, Johnson AL, Deshazer JA: Plasma progesterone, luteinizing hormone concentrations, and granulosa cell responsiveness in heat-stressed hens. Poultry science 1991, 70(11):2335-2339.

3. Shimizu T, Ohshima I, Ozawa M, Takahashi S, Tajima A, Shiota M, Miyazaki H, Kanai Y: Heat stress diminishes gonadotropin receptor expression and enhances susceptibility to apoptosis of rat granulosa cells. Reproduction 2005, 129(4):463-472. 
4. Chand N, Muhammad S, Khan RU, Alhidary IA, Rehman ZU: Ameliorative effect of synthetic gamma-aminobutyric acid (GABA) on performance traits, antioxidant status and immune response in broiler exposed to cyclic heat stress. Environ Sci Pollut Res Int 2016, 23(23):23930-23935.

5. Luo X, Zheng C, Xia W, Ruan D, Wang S, Cui Y, Yu D, Wu Q, Huang D, Zhang Y et al: Effects of constant or intermittent high temperature on egg production, feed intake, and hypothalamic expression of antioxidant and pro-oxidant enzymes genes in laying ducks. Journal of animal science 2018, 96(12):5064-5074.

6. Mashaly MM, Hendricks GL, 3rd, Kalama MA, Gehad AE, Abbas AO, Patterson PH: Effect of heat stress on production parameters and immune responses of commercial laying hens. Poult Sci 2004, 83(6):889-894.

7. Star L, Juul-Madsen HR, Decuypere E, Nieuwland MG, de Vries Reilingh G, van den Brand $\mathrm{H}$, Kemp B, Parmentier HK: Effect of early life thermal conditioning and immune challenge on thermotolerance and humoral immune competence in adult laying hens. Poultry science 2009, 88(11):2253-2261.

8. Zhu L, Liao R, Wu N, Zhu G, Yang C: Heat stress mediates changes in fecal microbiome and functional pathways of laying hens. Applied microbiology and biotechnology 2019, 103(1):461-472.

9. Min Z, Xiao-Ting Z, Hui L, Xin-Yang D, Wenjing Z: Effect of dietary $Y$-aminobutyric acid on laying performance, egg quality, immune activity and endocrine hormone in heat-stressed Roman hens. Animal Science Journal 2012, 83(2):141-147.

10. Laudadio V, Dambrosio A, Normanno G, Khan RU, Naz S, Rowghani E, Tufarelli V: Effect of reducing dietary protein level on performance responses and some microbiological aspects of broiler chickens under summer environmental conditions. Avian Biology Research 2012, 5(2):88-92.

11. Dowarah R, Sethi APS: Various dietary levels of protein and energy interaction on growth performance of white plumage Japanese quails. Veterinary World 2014, 7(6):398-402.

12. Chand N, Muhammad S, Khan RU, Alhidary IA, Rehman ZU: Ameliorative effect of synthetic $\gamma$-aminobutyric acid (GABA) on performance traits, antioxidant status and immune response in broiler exposed to cyclic heat stress. Environmental Science \& Pollution Research 2016, 23(23):23930-23935.

13. Abd El-Hack ME, Mahrose K, Arif M, Chaudhry MT, Saadeldin IM, Saeed M, Soomro RN, Abbasi $I H$, Rehman $\mathrm{ZU}$ : Alleviating the environmental heat burden on laying hens by feeding on diets enriched with certain antioxidants (vitamin E and selenium) individually or combined. Environmental science and pollution research international 2017, 24(11):10708-10717.

14. Galli GM, Da Silva AS, Biazus AH, Reis JH, Boiago MM, Topazio JP, Migliorini MJ, Guarda NS, Moresco RN, Ourique AF et al: Feed addition of curcumin to laying hens showed anticoccidial effect, and improved egg quality and animal health. Res Vet Sci 2018, 118:101-106.

15. Xiao YQ, Shao D, Tong HB, Shi SR: Genistein increases progesterone secretion by elevating related enzymes in chicken granulosa cells. Poult Sci 2019, 98(4):1911-1917.

16. Mazanko MS, Makarenko MS, Chistyakov VA, Usatov AV, Prazdnova EV, Bren AB, Gorlov 
IF, Komarova ZB, Weeks R, Chikindas ML: Probiotic Intake Increases the Expression of Vitellogenin Genes in Laying Hens. Probiotics Antimicrob Proteins 2019.

17. Qiao H, Zhang L, Shi H, Song Y, Bian C: Astragalus affects fecal microbial composition of young hens as determined by 16S rRNA sequencing. AMB Express 2018, 8(1):70.

18. Sang S, Lambert JD, Ho CT, Yang CS: The chemistry and biotransformation of tea constituents. Pharmacological Research 2011, 64(2):87-99.

19. Qian YE, Ramamurthy S: Molecular understanding of Epigallocatechin gallate (EGCG) in cardiovascular and metabolic diseases. Journal of Ethnopharmacology 2017, 210:296.

20. Wang XC, Wang XH, Wang J, Wang H, Zhang HJ, Wu SG, Qi GH: Dietary tea polyphenol supplementation improved egg production performance, albumen quality, and magnum morphology of $\mathrm{Hy}$-Line Brown hens during the late laying period. Journal of animal science 2018, 96(1):225-235.

21. Wang Q, Zhang J, Li Y, Shi H, Wang H, Chen B, Wang F, Wang Z, Yang Z, Wang L: Green tea polyphenol epigallocatechin-3-gallate increases atherosclerotic plaque stability in apolipoprotein E-deficient mice fed a high-fat diet. Kardiol Pol 2018, 76(8):1263-1270.

22. Juszkiewicz A, Glapa A, Basta P, Petriczko E, Zolnowski K, Machalinski B, Trzeciak J, Luczkowska K, Skarpanska-Stejnborn A: The effect of L-theanine supplementation on the immune system of athletes exposed to strenuous physical exercise. J Int SoC Sports Nutr 2019, 16(1):7.

23. Shunyu S, Dongshan T, Yongding L: Effects of an algicidal bacterium Pseudomonas mendocina on the growth and antioxidant system of Aphanizomenon flos-aquae. Current Microbiology 2009, 59(2):107-112.

24. Zhang GF, Yang ZB, Wang Y, Yang WR, Jiang SZ, Gai GS: Effects of ginger root (Zingiber officinale) processed to different particle sizes on growth performance, antioxidant status, and serum metabolites of broiler chickens. Poultry Science 2013, 92(1):178-183.

25. Wang L, ., Piao XL, Kim SW, Piao XS, Shen YB, Lee HS: Effects of Forsythia suspensa extract on growth performance, nutrient digestibility, and antioxidant activities in broiler chickens under high ambient temperature. Poultry Science 2008, 87(7):1287.

26. Ren N, Kim E, Li B, Pan H, Tong T, Yang CS, Tu Y: Flavonoids alleviating insulin resistance through inhibition of inflammatory signaling. J Agric Food Chem 2019.

27. Haqqi TM, Anthony DD, Gupta S, Ahmad N, Lee MS, Kumar GK, Mukhtar H: Prevention of collagen-induced arthritis in mice by a polyphenolic fraction from green tea. Proc Natl Acad Sci U S A 1999, 96(8):4524-4529.

28. Sakagami H, Watanabe T, Hoshino T, Suda N, Mori K, Yasui T, Yamauchi N, Kashiwagi H, Gomi T, Oizumi T et al: Recent Progress of Basic Studies of Natural Products and Their Dental Application. Medicines (Basel) 2018, 6(1).

29. Kanlaya R, Thongboonkerd V: Protective Effects of Epigallocatechin-3-Gallate from Green Tea in Various Kidney Diseases. Adv Nutr 2019, 10(1):112-121.

30. Zhang S, Zhao Y, Ohland C, Jobin C, Sang S: Microbiota facilitates the formation of the aminated metabolite of green tea polyphenol (-)-epigallocatechin-3-gallate which trap deleterious reactive endogenous metabolites. Free Radic Biol Med 2018, 
131:332-344.

31. Zhang M, Zhang X, Ho CT, Huang Q: Chemistry and Health Effect of Tea Polyphenol (-)-Epigallocatechin 3- 0-(3- O-Methyl)gallate. Journal of agricultural and food chemistry 2018.

32. Ikuko K, Mari MY, Hirofumi T, Masanori K: Antihypertensive effect of Benifuuki tea containing O-methylated EGCG. Journal of Agricultural \& Food Chemistry 2010, 58(3):1903.

33. Salami SA, Majoka MA, Saha S, Garber A, Gabarrou JF: Efficacy of dietary antioxidants on broiler oxidative stress, performance and meat quality: Science and market. Avian Biology Research 2015, 8(2):65-78.

34. Zhang L, Bai K, Zhang J, Xu W, Huang Q, Wang T: Dietary effects of Bacillus subtilis fmbj on the antioxidant capacity of broilers at an early age. Poultry Science 2017, 96(10):3564.

35. Lin $\mathrm{H}$, Decuypere $\mathrm{E}$, Buyse J: Acute heat stress induces oxidative stress in broiler chickens. Comparative Biochemistry \& Physiology Part A Molecular \& Integrative Physiology 2006, 144(1):11-17.

36. Grzesik M, Bartosz G, Stefaniuk I, Pichla M, Namiesnik J, Sadowska-Bartosz I: Dietary antioxidants as a source of hydrogen peroxide. Food Chem 2019, 278:692-699.

37. Akazome $\mathrm{Y}, \mathrm{Abe} \mathrm{T}$, Mori $\mathrm{T}$ : Differentiation of chicken gonad as an endocrine organ: expression of $\mathrm{LH}$ receptor, $\mathrm{FSH}$ receptor, cytochrome $\mathrm{P} 450 \mathrm{c} 17$ and aromatase genes. Reproduction 2002, 123(5):721-728.

38. Hernandez AG, Bahr JM: Role of FSH and epidermal growth factor (EGF) in the initiation of steroidogenesis in granulosa cells associated with follicular selection in chicken ovaries. Reproduction 2003, 125(5):683-691.

39. Long L, Wu SG, Yuan F, Zhang HJ, Wang J, Qi GH: Effects of dietary octacosanol supplementation on laying performance, egg quality, serum hormone levels, and expression of genes related to the reproductive axis in laying hens. Poult Sci 2017, 96(4):894-903.

40. Picazo RA, Garcia Ruiz JP, Santiago Moreno J, Gonzalez de Bulnes A, Munoz J, Silvan G, Lorenzo PL, Illera JC: Cellular localization and changes in expression of prolactin receptor isoforms in sheep ovary throughout the estrous cycle. Reproduction 2004, 128(5):545-553.

41. Thompson IR, Kaiser UB: GnRH pulse frequency-dependent differential regulation of LH and FSH gene expression. Mol Cell Endocrino/2014, 385(1-2):28-35.

42. Wataru T, Itoh MT, Nao S: Effects of $5 \alpha$-dihydrotestosterone and $17 \beta$-estradiol on the mouse ovarian follicle development and oocyte maturation. Plos One 2014, 9(6):e99423.

43. Mohammadi $H$, Ansari-Pirsaraei $Z$ : Changes in some blood parameters and production performance of old laying hens due to growth hormone and testosterone injection. Journal of Animal Physiology \& Animal Nutrition 2014, 98(3):483-490.

44. SQUIRES, E.J: Applied Animal Endocrinology; 2010.

45. Smith SM, Vale WW: The role of the hypothalamic-pituitary-adrenal axis in neuroendocrine responses to stress. Dialogues in Clinical Neuroscience 2006, 
8(4):383-395.

46. Gurung S, White D, Archer G, Styles D, Zhao D, Farnell Y, Byrd J, Farnell M: Carbon Dioxide and Nitrogen Infused Compressed Air Foam for Depopulation of Caged Laying Hens. Animals An Open Access Journal from Mdpi 2018, 8(1):6-.

47. Guo R, Zhou FM, Su CJ, Liu TT, Zhou Y, Fan L, Wang ZH, Liu X, Huang Y, Liu T et al: Epigallocatechin-3-gallate attenuates acute and chronic psoriatic itch in mice: Involvement of antioxidant, anti-inflammatory effects and suppression of ERK and Akt signaling pathways. Biochem Biophys Res Commun 2018, 496(4):1062-1068.

48. Zhang S, Al-Maghout T, Bissinger R, Zeng N, Pelzl L, Salker MS, Cheng A, Singh Y, Lang F: Epigallocatechin-3-gallate (EGCG) up-regulates miR-15b expression thus attenuating store operated calcium entry (SOCE) into murine CD4(+) T cells and human leukaemic T cell lymphoblasts. Oncotarget 2017, 8(52):89500-89514.

49. Perot M, Lupi R, Guyot S, Delayre-Orthez C, Gadonna-Widehem P, Thebaudin JY, Bodinier M, Larre C: Polyphenol Interactions Mitigate the Immunogenicity and Allergenicity of Gliadins. J Agric Food Chem 2017, 65(31):6442-6451.

50. Liu X, Peng C, Qu X, Guo S, Chen JF, He C, Zhou X, Zhu S: Effects of Bacillus subtilis C-3102 on production, hatching performance, egg quality, serum antioxidant capacity and immune response of laying breeders. J Anim Physiol Anim Nutr (Berl) 2018.

51. Zhao $Y$, Wu XY, Xu SX, Xie JY, Xiang KW, Feng L, Liu Y, Jiang WD, Wu P, Zhao J et al: Dietary tryptophan affects growth performance, digestive and absorptive enzyme activities, intestinal antioxidant capacity, and appetite and GH-IGF axis-related gene expression of hybrid catfish (Pelteobagrus vachellifemale symbol $x$ Leiocassis longirostrismale symbol). Fish Physiol Biochem 2019.

52. Ni H, Peng L, Gao X, Ji H, Ma J, Li Y, Jiang S: Effects of maduramicin on adult zebrafish (Danio rerio): Acute toxicity, tissue damage and oxidative stress. Ecotoxicol Environ Saf 2019, 168:249-259.

53. Rimoldi S, Lasagna E, Sarti FM, Marelli SP, Cozzi MC, Bernardini G, Terova G: Expression profile of six stress-related genes and productive performances of fast and slow growing broiler strains reared under heat stress conditions. Meta Gene 2015, 6:17-25.

54. Aulitzky W, Gastl G, Aulitzky WE, Herold M, Kemmler J, Mull B, Frick J, Huber C: Successful treatment of metastatic renal cell carcinoma with a biologically active dose of recombinant interferon-gamma. J Clin Onco/1989, 7(12):1875-1884.

55. Zhou Y, Chen X, Yi R, Li G, Sun P, Qian Y, Zhao X: Immunomodulatory Effect of Tremella Polysaccharides against Cyclophosphamide-Induced Immunosuppression in Mice. Molecules 2018, 23(2).

56. Heiler S, Lotscher J, Kreuzaler M, Rolink J, Rolink A: Prophylactic and Therapeutic Effects of Interleukin-2 (IL-2)/Anti-IL-2 Complexes in Systemic Lupus Erythematosus-Like Chronic Graft-Versus-Host Disease. Front Immuno/ 2018, 9:656.

57. Mahfuz S, Song H, Miao Y, Liu Z: Dietary inclusion of mushroom (Flammulina velutipes) stem waste on growth performance and immune responses in growing layer hens. J Sci Food Agric 2019, 99(2):703-710.

58. Wen ZS, Tang Z, Gu LX, Xiang XW, Qu YL: Immunomodulatory effect of low 
molecular-weight seleno-aminopolysaccharide on immunosuppressive mice. Int $J$ Biol Macromo/ 2019, 123:1278-1288.

\section{Chart Legends}

Table 1 Composition and nutrition levels of the basal diet (fed basis, \%)

Table 2 Gene-specific primers used in the real-time quantitative chain reaction

Table 3 Effects of tea polyphenol on parameters of serum in laying hens

Data with different superscript letters are significantly different $(\mathrm{P}<0.05)$.

Table 4 Effects of tea polyphenol on serum antioxidant index of laying hens

Table 5 Effects of tea polyphenol on hormone levels of laying hens

Data with different superscript letters are significantly different $(\mathrm{P}<0.05)$

Table 6 Effects of tea polyphenol on immune parameters in laying hens

Data with different superscript letters are significantly different $(\mathrm{P}<0.05)$

Figure 1. The mRNA expressions of SOD, GSH-Px, CAT, and HSP90 after 42 days of heat exposure in the liver of hens.

*: Means differ significantly, $\mathrm{P}<0.05$.

Figure 2. The mRNA expressions of INF, IL-2, and IL-4 after 42 days of heat exposure in the spleen of hens.

**: Means differ extremely significant, $\mathrm{P}<0.01$.

Table 1 Composition and nutrition levels of the basal diet (fed basis, \%) 


\begin{tabular}{lrlr}
\hline Ingredients (\%) & \multicolumn{1}{c}{ content } & Analyzed nutrient & content \\
\hline Corn & 62.00 & ME (MJ/kg) + & 11.20 \\
Soybean meal & 22.00 & $\mathrm{CP}$ & 17.00 \\
Wheat bran & 3.00 & $\mathrm{EE}$ & 6.32 \\
Limestone & 8.00 & Lys & 0.78 \\
Premix $\dagger$ & 3.00 & Met+Cys & 0.68 \\
NaCl & 0.40 & Met & 0.54 \\
Calcium hydrophosphate & 1.60 & Ca & 3.52 \\
Total & 100.00 & P & 0.48 \\
\hline
\end{tabular}

†The premix provides the following per kg diet: vitamin A $7000 \mathrm{IU}$; vitamin D $32500 \mathrm{IU}$; vitamin E $36 \mathrm{mg}$; vitamin K 32 mg;vitamin B12 mg; vitamin B2 $5.6 \mathrm{mg}$; vitamin B6 $4 \mathrm{mg}$; vitaminB12 $0.025 \mathrm{mg}$; nicotinic acid $38 \mathrm{mg}$; folic acid $1.1 \mathrm{mg}$; calcium pantothenate 10 mg; biotin 0.16 mg; Cu 10 mg; Fe 80 mg; Mn 100 mg; Zn 60 mg; I 0.55 mg; Se 0.12 mg. łValues are deterministic values except ME.

$\mathrm{ME}$, metabolic energy; $\mathrm{CP}$, crude protein; EE, ether extract; Lys, lysine; Met, methionine; Cys,cysteine.

Table 2 Gene-specific primers used in the real-time quantitative chain reaction

\begin{tabular}{|c|c|c|c|}
\hline Gene & Accession no. & Sequences $\left(5^{\prime} \rightarrow 3^{\prime}\right)$ & Product size (bp) \\
\hline \multirow[t]{2}{*}{ SOD1 } & \multirow{2}{*}{ NM 205,064.1 } & F: TTGTCTGATGGAGATCATGGCTTC & \multirow[t]{2}{*}{98} \\
\hline & & R:TGCTTGCCTTCAGGATTAAAGTGAG & \\
\hline \multirow[t]{2}{*}{ GPX1 } & \multirow[t]{2}{*}{ NM $0,012,77853.1$} & F: TCACCATGTTCGAGAAGTGC & \multirow[t]{2}{*}{124} \\
\hline & & R: ATGTACTGCGGGTTGGTCAT & \\
\hline \multirow[t]{2}{*}{ CAT } & \multirow[t]{2}{*}{ NM 0,010,31215.1 } & F: GTTGGCGGTAGGAGTCTGGTCT & \multirow[t]{2}{*}{182} \\
\hline & & R: GTGGTCAAGGCATCTGGCTTCTG & \\
\hline \multirow[t]{2}{*}{ HSP90 } & \multirow[t]{2}{*}{ NM 423463} & F: GGTGTTGGTTCCTACTCTGCTTAC & \multirow[t]{2}{*}{372} \\
\hline & & R: ACTGCTCATCATCATTGTGCTTGG & \\
\hline \multirow[t]{2}{*}{ IL-2 } & \multirow[t]{2}{*}{ NM_008366 } & F: TCAGCAACTGTGGTGGACTT & \multirow[t]{2}{*}{106} \\
\hline & & R: GCCTTATGTGTTGTAAGCAGGA & \\
\hline \multirow[t]{2}{*}{ IL-4 } & \multirow{2}{*}{ NM_021283 } & F: GTTCTTCGTTGCTGTGAGGAC & \multirow[t]{2}{*}{135} \\
\hline & & R: TGTACCAGGAGCCATATCCAC & \\
\hline \multirow[t]{2}{*}{ INF- $\gamma$} & \multirow[t]{2}{*}{ NM_008337 } & F:TAACTCAAGTGGCATAGATGTGGAAG & \multirow[t]{2}{*}{169} \\
\hline & & R: GACGCTTATGTTGTTGCTGATGG & \\
\hline \multirow[t]{2}{*}{$\beta$-actin } & \multirow[t]{2}{*}{ NM 205,518.1 } & F: CTACACACGGACACTTCAAG & \multirow[t]{2}{*}{244} \\
\hline & & R: ACAAACATGGGGGCATCAG & \\
\hline
\end{tabular}

SOD1, Superoxide dismutase 1; GPX1, Glutathione peroxidase 1; CAT, Catalase; HSP90, Heat shock protein 90; IL-2, Interleukin 2; IL-4, Interleukin 4; INF- $\gamma$, Interferon- $\gamma$.

Table 3 Effects of tea polyphenol on parameters of serum in laying hens

\begin{tabular}{lll}
\hline item & Control & Treatment \\
\hline AST(U/L) & $316.4 \pm 27.38$ & $300.4 \pm 26.18$ \\
ALT(U/L) & $10.75 \pm 1.44$ & $11.25 \pm 2.14$ \\
TP(g/L) & $50.6 \pm 0.98^{\mathrm{a}}$ & $45.8 \pm 1.16^{\mathrm{b}}$ \\
$\mathrm{ALB}(\mathrm{g} / \mathrm{L})$ & $25.2 \pm 1.07$ & $25.6 \pm 0.4$ \\
\hline
\end{tabular}




\begin{tabular}{lll}
\hline $\mathrm{ALP}(\mathrm{U} / \mathrm{L})$ & $600.25 \pm 61.1$ & $768.25 \pm 37.19$ \\
$\mathrm{TG}(\mathrm{mmol} / \mathrm{L})$ & $7.81 \pm 0.87$ & $8.82 \pm 0.87$ \\
$\mathrm{CHO}(\mathrm{mmol} / \mathrm{L})$ & $3.66 \pm 0.17$ & $3.32 \pm 0.3$ \\
$\mathrm{GLU}(\mathrm{mmol} / \mathrm{L})$ & $12.4 \pm 0.12$ & $12.59 \pm 0.19$ \\
$\mathrm{HDL}-\mathrm{C}(\mathrm{mmol} / \mathrm{L})$ & $1.83 \pm 0.05^{\mathrm{a}}$ & $0.84 \pm 0.23^{\mathrm{b}}$ \\
$\mathrm{LDL}-\mathrm{C}(\mathrm{mmol} / \mathrm{L})$ & $0.08 \pm 0.01$ & $0.06 \pm 0.01$ \\
$\mathrm{UA}(\mathrm{mmol} / \mathrm{L})$ & $341.6 \pm 26.16$ & $343.6 \pm 61.96$ \\
$\mathrm{GREA}(\mathrm{mmol} / \mathrm{L})$ & $5 \pm 1.14$ & $4.4 \pm 0.98$ \\
\hline
\end{tabular}

Values are the mean \pm SE of 6 hens. Data with different superscript letters are significantly different $(\mathrm{P}<0.05)$.AST, aspartate aminotransferase; ALT , aminotransferase; ALP , alkaline phosphatasealanine ; ALB, albumin; TP, total protein; TG, triglyceride; $\mathrm{CHO}$, cholesterol; GLU, glucose; HDL-C, high density protein and LDL-C ,low density protein .

Table 4 Effects of tea polyphenol on serum antioxidant index of laying hens

\begin{tabular}{lll}
\hline item & Control & Treatment \\
\hline SOD $(\mathrm{U} / \mathrm{ml})$ & $12.83 \pm 0.24$ & $13.01 \pm 0.05$ \\
GSH-PX $(\mathrm{U})$ & $9.78 \pm 1.3$ & $11.92 \pm 0.87$ \\
CAT $(\mathrm{U} / \mathrm{ml})$ & $5.1 \pm 0.66$ & $5.84 \pm 0.82$ \\
MDA $(\mathrm{nmol} / \mathrm{ml})$ & $7.1 \pm 0.8$ & $6.98 \pm 0.73$ \\
\hline
\end{tabular}

Values are the mean $\pm S E$ of 6 hens. Data with different superscript letters are significantly different $(\mathrm{P}<0.05)$. GSH-Px, glutathione Peroxidase; SOD, superoxide dismutase; CAT, Catalase; MDA, malondialdehyde.

Table 5 Effects of tea polyphenol on hormone levels of laying hens

\begin{tabular}{lll}
\hline item & Control & Treatment \\
\hline COR(ug/L) & $188.74 \pm 6.4^{\mathrm{a}}$ & $165.14 \pm 5.53^{\mathrm{b}}$ \\
E2(ug/L) & $401.35 \pm 20.22$ & $451.69 \pm 18.35$ \\
FSH(ug/L) & $3.79 \pm 0.08^{\mathrm{b}}$ & $4.44 \pm 0.18^{\mathrm{a}}$ \\
LH & $14.51 \pm 0.61$ & $16.41 \pm 0.9$ \\
\hline
\end{tabular}

Values are the mean \pm SE of 6 hens. Data with different superscript letters are significantly different $(\mathrm{P}<0.05)$. COR, corticosterone; FSH, follicle stimulating hormone; E2, estradiol; PRL, prolactin; LH, luteinizing hormone 。

Table 6 Effects of tea polyphenol on immune parameters in laying hens

\begin{tabular}{lll}
\hline item & Control & Treatment \\
\hline $\operatorname{IgA}(\mathrm{ug} / \mathrm{mL})$ & $243.73 \pm 19.4$ & $267.44 \pm 15.62$ \\
$\mathrm{IgG}(\mathrm{ug} / \mathrm{mL})$ & $310.08 \pm 26.23^{\mathrm{b}}$ & $424.06 \pm 17.37^{\mathrm{a}}$ \\
$\mathrm{IgM}(\mathrm{ug} / \mathrm{mL})$ & $2.75 \pm 0.11^{\mathrm{b}}$ & $3.62 \pm 0.32^{\mathrm{a}}$ \\
$\mathrm{C} 3(\mathrm{ug} / \mathrm{mL})$ & $1466.37 \pm 60.8$ & $1461.46 \pm 37.59$ \\
$\mathrm{C} 4(\mathrm{ug} / \mathrm{mL})$ & $908.17 \pm 70.09$ & $868.38 \pm 41.39$ \\
$\mathrm{IL6}(\mathrm{ng} / \mathrm{L})$ & $20.88 \pm 1.66$ & $21.77 \pm 0.85$ \\
\hline
\end{tabular}

Values are the mean \pm SE of 6 hens. Data with different superscript letters are significantly different $(\mathrm{P}<0.05)$. 


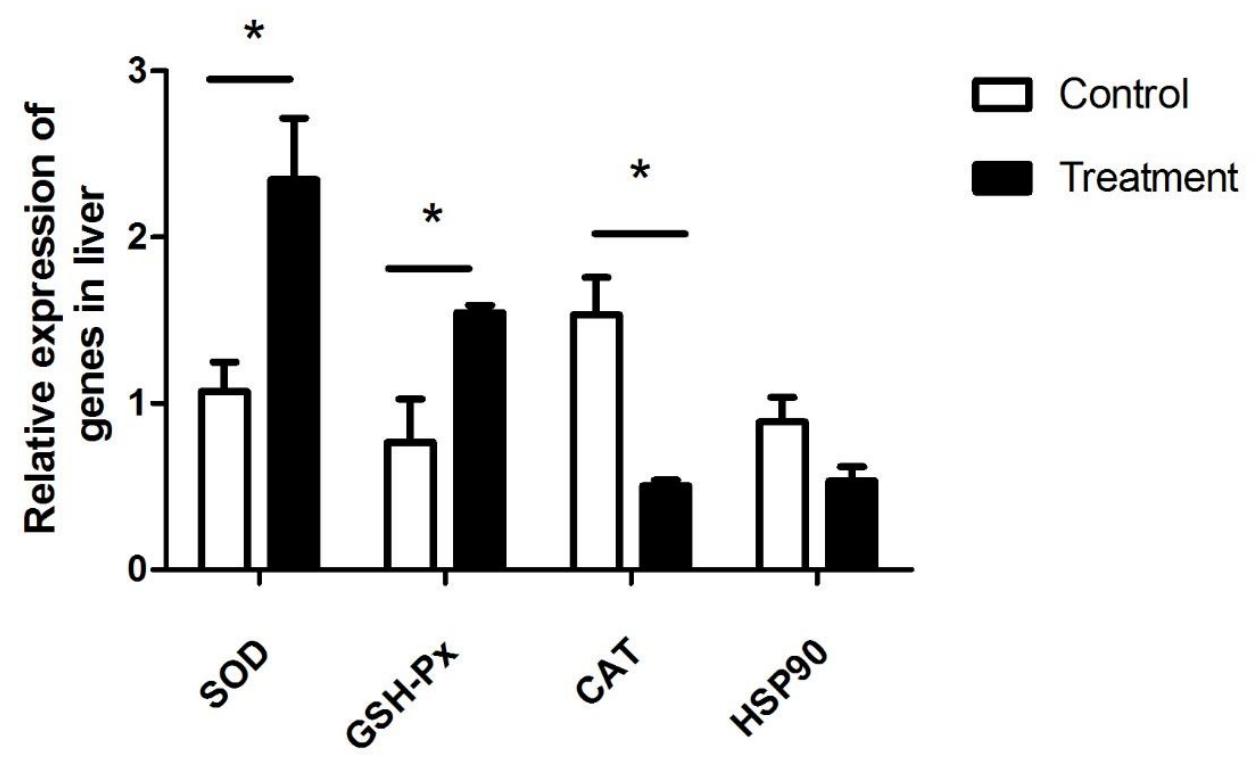

Figure 1. The mRNA expressions of SOD, GSH-Px, CAT, and HSP90 after 42 days of heat exposure in the liver of hens. Each result represents the mean value \pm SEM $(n=6)$; *: Means differ significantly, $\mathrm{P}<$ 0.05. Control, heat-stress group; Treatment, feed tea polyphenol group. SOD, Superoxide dismutase; GSH-Px, Glutathione peroxidase; CAT, Catalase; HSP90, Heat shock protein 90.

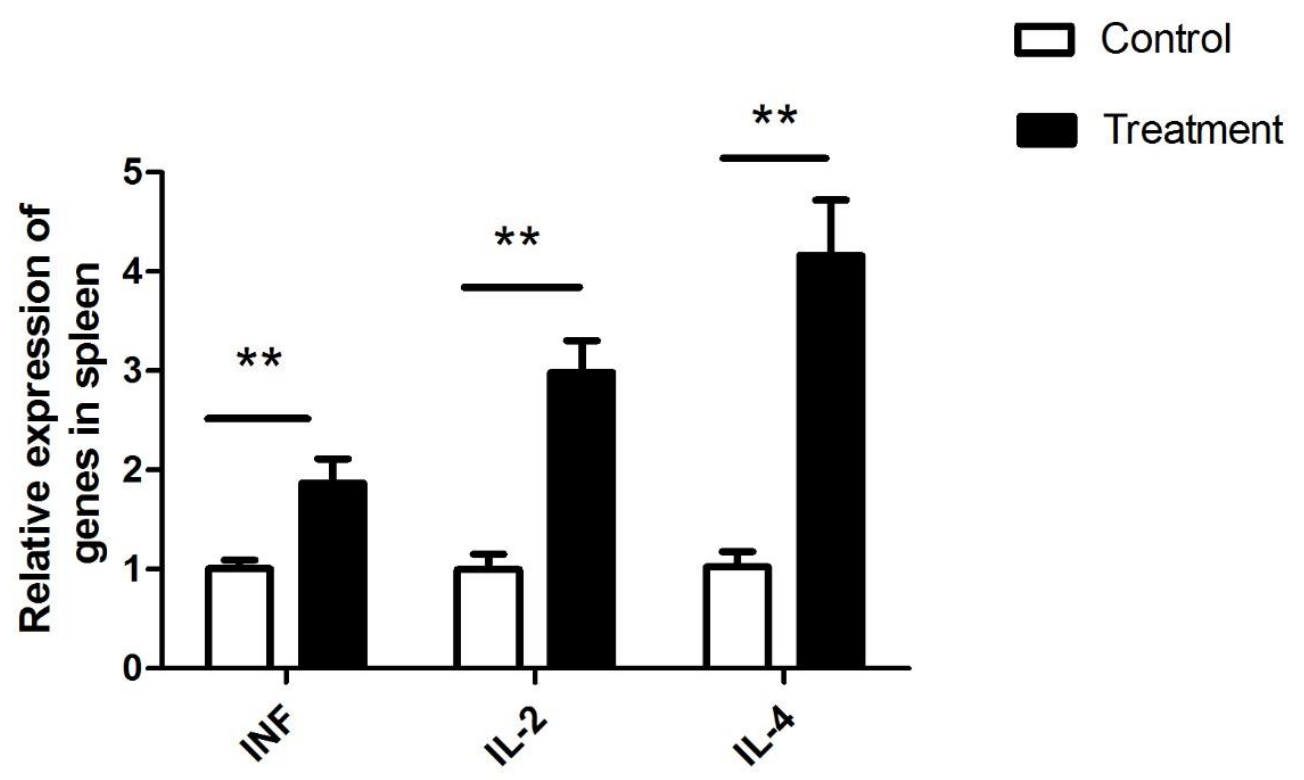

Figure 2. The mRNA expressions of INF, IL-2, and IL-4 after 42 days of heat exposure in the spleen of hens. Each result represents the mean value $\pm \operatorname{SEM}(n=6) ;{ }^{* *}$ : Means differ extremely significant, $\mathrm{P}<0.01$. Control, heat-stress group; Treatment, feed tea polyphenol group. INF, Interferon- $\gamma$; IL-2, Interleukin 2; IL-4, Interleukin 4. 